\title{
Penerapan Data Mining Classification untuk Data Blogger Menggunakan Metode Naïve Bayes
}

\author{
Recha Abriana Anggraini ${ }^{*}$, Galih Widagdo ${ }^{*}$, Arief Setya Budi ${ }^{*}$, M. Qomaruddin ${ }^{* 4}$ \\ *Program Studi Sistem Informasi STMIK Nusa Mandiri \\ Jakarta Pusat \\ ${ }^{1}$ anggrainirecha@gmail.com \\ galihwidagdo19@gmail.com \\ ${ }^{3}$ ariefsetya334@gmail.com \\ ${ }^{4}$ qomaruddin.mqnabsi.ac.id
}

\begin{abstract}
Abstrak - Jumlah pengguna situs blogger yang semakin meningkat menyebabkan perlu dilakukan pengklasifikasian data untuk mengetahui pengguna tersebut masuk dalam kategori pengguna blogger professional atau bukan. Sebagai referensi terkait penelitian ini adalah penelitian yang sudah dilakukan oleh peneliti sebelumnya. Teknik pengklasifikasian pemodelan deskriptif dan prediktif dengan algoritma data mining yaitu menggunakan metode naïve bayes. Untuk mengelola data digunakan software rapid miner studio 6.0, dataset blogger diperoleh dari website UCI Machine learning Repository, Perhitungan performance vector menunjukkan akurasi klasifikasi metode Naive bayes diperoleh sebesar $86.67 \%$. Sedangkan class precision dan class recall untuk prediksi yes menunjukkan tingkat precision sebesar $91.30 \%$ dan untuk prediksi no sebesar $71.43 \%$. Hasil klasifikasi dari data blogger dengan metode naïve bayes membagi 2 kelas klasifikasi PB yaitu class yes dan class no. Untuk nilai class yes yaitu 0.680 dan nilai class no yaitu 0.320. Dari hasil pengolahan data dapat diketahui bahwa tingkat akurasi pengklasifikasian data blogger mencapai $86.67 \%$.
\end{abstract}

Kata kunci- Nä̈ve Bayes, Data Mining, Klasifikasi, Blogger, Rapid Miner

\section{PENDAHULUAN}

Perkembangan teknologi dalam bidang informasi yang sangat pesat pada saat ini diharapkan dapat memberikan kemudahan bagi manusia dalam mencari dan menyebarkan informasi yang bermanfaat dan dibutuhkan bagi kehidupan. Pencarian dan penyebaran informasi dapat dilakukan melalui berbagai media, namun yang paling populer adalah melalui media website dengan memanfaatkan teknologi internet.

Salah satu layanan website yang berguna untuk mencari dan menyebarkan informasi yang paling populer adalah situs blogger. Berdasarkan data statistik dari ASEAN blogger yang dikutip oleh Tempo 2013 menyebutkan bahwa pada tahun 2008 terdapat 500 ribu blogger aktif di Indonesia, sedangkan dilansir dari antaranews.com pengguna blogger di Indonesia pada tahun 2015 sekitar 3 juta pengguna. Berdasarkan data tersebut dapat disimpulkan bahwa pengguna situs blogger di Indonesia semakin meningkat, hal itu juga menyebabkan penyebaran informasi semakin beraneka ragam.

Jumlah pengguna situs blogger yang semakin meningkat menyebabkan perlu dilakukan pengklasifikasian data berdasarkan beberapa faktor untuk mengetahui pengguna tersebut masuk dalam kategori pengguna blogger professional atau bukan.

Berdasarkan fenomena tersebut maka dilakukan penelitian dengan menggunakan teknik data mining untuk melakukan klasifikasi data dengan algoritma naïve bayes. Penelitian yang digunakan sebagai referensi panduan terkait penelitian ini adalah penelitian yang dilakukan oleh Ardiyansyah, Panny Agustia Rahayuningsih, dan Reza Maulana yang berjudul analisis perbandingan algoritma klasifikasi data mining untuk dataset blogger dengan rapid miner (Ardiyansyah, Rahayuningsih, \& Maulana, 2018).

\section{TINJAUAN PUSTAKA}

A. Knowledge Discovery in Database (KDD)

Knowledge Discovery in Database (KDD) adalah penemuan atau pencarian pengetahuan (nilai tambah) di dalam sebuah database, karena data mining adalah suatu rangkaian proses (Sari \& Saro, 2018).

\section{B. Data Mining}

Data mining adalah suatu proses menemukan hubungan yang berarti, pola, dan kecenderungan dengan memeriksa dalam sekumpulan besar data yang tersimpan dalam pemyimpanan dengan menggunakan teknik pengenalan pola seperti teknik statistik dan matematika (Darmawan, Kustian, Rahayu, \& Tabebuya, 2018). 
Data mining berisi pencarian trend atau pola yang diinginkan dalam database besar untuk membantu pengambilan keputusan di waktu yang akan datang (Hermawati, 2013).

\section{Dataset}

Himpunan data (dataset) merupakan kumpulan dari objek dan atributnya (Hermawati, 2013). Dalam dataset, jenis data dapat dibagi menjadi 2 bagian yaitu:

\section{Data Training}

Data training adalah data yang digunakan untuk perhitungan probabilitas dari data berdasarkan data pembelajaran yang dilakukan (Pratiwi \& Nugroho, 2016). Data training merupakan data yang sebelumnya sudah ada sesuai dengan fakta.

\section{Data Testing}

Data testing merupakan data yang akan atau sedang terjadi dan dipergunakan sebagai bahan uji yang sebelumnya sudah didapatkan pada data training (Pratiwi \& Nugroho, 2016). Data ini digunakan untuk mengukur sejauh mana klasifikasi berhasil melakukan klasifikasi dengan benar.

\section{D.. $\quad$ Nä̈ve Bayes}

Teori bayes adalah kondisi probabilitas suatu kejadian hipotesis bergantung pada kejadian lain sebagai bukti (Moriesta \& Ibrahim, 2017). Metode yang diadopsi dari nama penemunya yaitu Thomas Bayes pada tahun 1950. Pada dasarnya, teori tersebut menyatakan bahwa kejadian dimasa depan dapat diprediksi dengan syarat kejadian sebelumnya telah terjadi. Teori naïve bayes memiliki kemampuan klasifikasi yang serupa dengan decision tree dan neural network bahkan algoritma naïve bayes memiliki akurasi dan kecepatan yang tinggi saat diaplikasikan ke dalam database dengan data yang besar (Kusrini dan Luthfi, 2013). Secara umum teori naïve bayes ditulis dalam bentuk (Saleh \& Nasari, 2018) :

$$
P(H \mid X)=\frac{P(X \mid H) \cdot P(H)}{P(X)}
$$

Keterangan :

$\mathrm{X} \quad$ : Data dengan class yang belum diketahui $\mathrm{H} \quad$ : Hipotesis data merupakan suatu class spesifik $\mathrm{P}(\mathrm{H} \mid \mathrm{X}) \quad$ : Probabilitas hipotesis $\mathrm{H}$ berdasar kondisi X (posteriori probabilitas)

$\mathrm{P}(\mathrm{H}) \quad$ : Probabilitas hipotesis $\mathrm{H}$ (prior probabilitas)

$\mathrm{P}(\mathrm{X} \mid \mathrm{H}) \quad$ : Probabilitas $\mathrm{X}$ berdasarkan kondisi pada hipotesis $\mathrm{H}$

$\mathrm{P}(\mathrm{X}) \quad$ : $\quad$ Probabilitas $\mathrm{X}$
Untuk menemukan kelas yang cocok bagi sampel yang dianalisis dalam proses klasifikasi, metode naïve bayes di atas disesuaikan sebagai berikut:

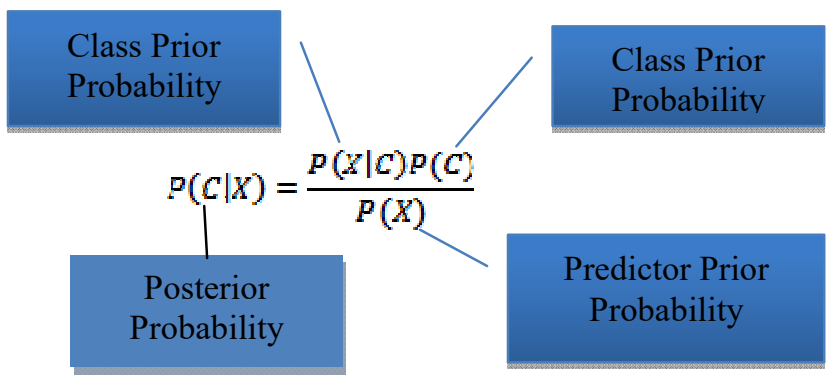

Gambar 1. Rumus Naive Bayes

Keterangan :

$\boldsymbol{x} \quad$ : Data dengan class yang belum diketahui

c : Hipotesis data merupakan suatu class spesifik

$\boldsymbol{P}(\boldsymbol{c} \mid \boldsymbol{x})$ : Probabilitas hipotesis berdasar kondisi (posteriori probability)

$\boldsymbol{P}(\boldsymbol{c}) \quad$ : Probabilitas hipotesis (prior probability)

$\boldsymbol{P}(\boldsymbol{x} \mid \boldsymbol{c}) \quad$ :Probabilitas berdasarkan kondisi pada hipotesis

$\boldsymbol{P}(\boldsymbol{x}) \quad$ : Probabilitas c

Rumus diatas menjelaskan bahwa peluang masuknya sampel karakteristik tertentu dalam kelas C (Posterior) adalah peluang munculnya kelas $\mathrm{C}$ (sebelum masuknya sampel tersebut, seringkali disebut prior), dikali dengan peluang kemunculan karakteristik karakteristik sampel pada kelas C (disebut juga likelihood), dibagi dengan peluang kemunculan karakteristik sampel secara global ( disebut juga evidence). Karena itu, rumus diatas dapat pula ditulis sebagai berikut :

$$
\text { Posterior }=\frac{\text { priar } x \text { likelihood }}{\text { evidence }} \text {.... [2] }
$$

Nilai Evidence selalu tetap untuk setiap kelas pada satu sampel. Nilai dari posterior tersebut nantinya akan dibandingkan dengan nilai nilai posterior kelas lainnya untuk menentukan ke kelas apa suatu sampel akan diklasifikasikan. Penjabaran lebih lanjut rumus Bayes tersebut dilakukan dengan menjabarkan $(c \mid x 1, \ldots, x n)$ menggunakan aturan perkalian sebagai berikut :

$$
\begin{aligned}
& P(C \mid X 1, \ldots, X n)=P(C) P(X 1, \ldots X n \mid C) \\
& =P(C) P(X 1 \mid C)(X 2, \ldots X n \mid C, X 1) \quad \ldots[3] \\
& =P(C) P(X 1 \mid C) P(X 2 \mid C, X 1)(X 3, \ldots, X n \mid C, X 1, X 2) \\
& =P(C) P(X 1 \mid C) P(X 2 \mid C, X 1) P(X 3 \mid C, X 1, X 2) \ldots P(X n \mid C, X 1, X 2, \ldots n-1
\end{aligned}
$$

Dapat dilihat bahwa hasil penjabaran tersebut menyebabkan semakin banyak dan semakin kompleksnya faktor faktor syarat yang mempengaruhi nilai probabilitas, yang hampir mustahil untuk dianalisa satu persatu. Akibatnya, perhitungan tersebut menjadi sulit untuk dilakukan. Disinilah digunakan asumsi independensi yang 
sangat tinggi (naif), bahwa masing masing petunjuk saling bebas (independen) satu sama lain. Dengan asumsi tersebut, maka berlaku suatu kesamaan sebagai berikut:

$$
\begin{aligned}
& P\left(c \mid X 1, \ldots, X n=P(C) \prod_{i=1}^{n} P(X i \mid C)\right. \\
& P(C \mid X)=P\left(X_{1} \mid C\right) \ldots P\left(X_{n} \mid c\right) P(c) \ldots[4]
\end{aligned}
$$

Persamaan diatas merupakan model dari Teorema Naive Bayes yang selanjutnya akan digunakan dalam proses klasifikasi. Untuk klasifikasi dengan data kontinyu digunakan rumus Densitas Gauss :

$$
P-\left(X_{i}-x_{i} \mid Y_{i}-y_{i}-\frac{1}{\sqrt{2 \pi \sigma_{i} j}} e^{-\frac{(K i-\mu i j) 2}{2 \sigma^{2} i j}}\right.
$$

\section{Keterangan :}

$\boldsymbol{P} \quad$ : Peluang

$\boldsymbol{X i} \quad$ : Atribut ke i

$\boldsymbol{x i} \quad$ : Nilai atribut ke i

$\boldsymbol{Y} \quad$ : Kelas yang dicari

$\boldsymbol{y} \quad$ : Sub kelas Y yang dicari

$\boldsymbol{u}$ : Mean, menyatakan rata rata dari seluruh atribut

o : Deviasi standar, menyatakan varian dari seluruh atribut

Mean

$$
\mu=\frac{1}{n} \sum_{i=1}^{n} x_{i} \quad \ldots . .[6]
$$

Deviasi Standar

$$
\sigma=\left[\frac{1}{n-1} \sum_{i=1}^{n}\left(x_{i}-u\right)^{2}\right]^{0.5} \ldots \ldots[7]
$$

Algoritma data mining naive bayes juga banyak digunakan pada penelitian-penelitian sebelumnya terutama untuk mengklasifikasikan data. Beberapa contoh penelitian terdahulu yang menggunakan algoritma naive bayes antaralain yaitu penelitian yang berjudul opinion mining untuk ulasan produk dengan klasifikasi naive bayes. Pada penelitian tersebut diketahui tingkat akurasi dari pengolahan data menggunakan metode naive bayes sebesar 77,7\% (Jeremy, A., Christanti, V., \& Mulyawan, 2018). Selain penelitian tersebut, penelitian lain yang menggunakan algoritma naive bayes berjudul algoritma naive bayes classifier pada aplikasi data mining berbasis web. Pada peelitian tersebut, diketahui hasil pengolahan datanya mencapai tingkat akurasi sebesar 83,00\% (Murdiyansyah \& Siswanto, 2018). Berdasarkan penelitian-penelitian yang terdahulu, yang menggunakan algoritma naive bayes peneliti mengetahui bahwa belum ada penelitian yang juga membuktikan hasilnya dengan pengujian manual. Sehingga pada penelitian ini, penulis mencoba untuk membuktikan hasil pengujian naive bayes dengan rapid miner dan juga hasil perhitungan naive bayes secara manual.

\section{METODOLOGI}

Penelitian ini menggunakan konsep data mining dengan bantuan software rapid miner studio 6.0. Dataset yang digunakan adalah dataset blogger yang diperoleh dari sebuah website yang menyediakan data publik yaitu UCI Machine learning Repository. Dataset blogger bersumber dari Kohkiloye dan Boyer Ahmad Province di Iran. Data tersebut akan digunakan sebagai data training dan data testing. Atribut yang terdapat pada dataset blogger yaitu Local Political Social Space (LPSS), Local Media Turnover (LMT), topics, Caprice, dan Degree. Sedangkan untuk class yang terdapat pada dataset tersebut yaitu Professional Blogger (PB) dengan nilai yes dan no. Teknik pengolahan dataset dalam penelitian ini menggunakan teknik klasifikasi dengan permodelan deskriptif dan prediktif menggunakan salah satu algoritma data mining yaitu metode naïve bayes.

\section{HASIL DAN PEMBAHASAN}

Dalam permodelan algoritma naïve bayes pada penelitian ini, data training diolah menggunakan model 10 fold serta cross validation. Jumlah responden dalam penelitian ini sebesar 100 responden, dengan dataset blogger ini peneliti akan mengklasifikasikan jenis blogger kedalam 2 kelompok yaitu Blogger Professional (BP) dan

\begin{tabular}{|c|c|c|c|c|c|}
\hline Degree & Caprice & Topics & Lmt & Lpss & $\mathrm{Pb}$ \\
\hline high & left & $\begin{array}{l}\text { impressi } \\
\text { on }\end{array}$ & yes & yes & yes \\
\hline high & left & political & yes & yes & yes \\
\hline medium & middle & tourism & yes & yes & yes \\
\hline high & left & political & yes & yes & yes \\
\hline medium & middle & news & yes & yes & yes \\
\hline medium & middle & news & yes & yes & yes \\
\hline high & left & political & yes & yes & yes \\
\hline high & right & political & yes & no & yes \\
\hline high & right & political & yes & no & no \\
\hline . & . & . & . & . & . \\
\hline . & . & . & . & . & . \\
\hline & & . & . & . & . \\
\hline low & right & $\begin{array}{l}\text { impressi } \\
\text { on }\end{array}$ & yes & no & no \\
\hline medium & right & news & yes & yes & no \\
\hline medium & left & $\begin{array}{l}\text { impressi } \\
\text { on }\end{array}$ & yes & yes & yes \\
\hline
\end{tabular}
Blogger Musiman (BM). Berikut merupakan data training dari dataset blogger:

TABEL 1.

DATA TRAINING DATASET BLOGGER

Tabel 1 merupakan dataset blogger yang dipakai sebagai data training dalam penelitian ini. Data tersebut berjumlah 100 data yang direpresentasikan dalam bentuk tabel. 


\section{PROSES DATA MINING}

A. Pemrosesan Awal

Dalam pemrosesan ini yang menjadi sasarannya adalah data blogger pada tahun 2013 yang akan menghasilkan grafik atau pola pengelompokkan blogger serta memperlihatkan prediksi pengguna blogger pada tahun yang akan datang.

Pembuatan model diawali dengan pembacaan file data (read excel). Data training disimpan dalam satu file excel kemudian data tersebut divalidasi menggunakan cross validation.

TABEL 2.

DATA TRAINING

\begin{tabular}{|c|c|c|c|c|c|}
\hline Degree & Caprice & Topics & $\mathrm{Lmt}$ & Lpss & $\mathrm{Pb}$ \\
\hline high & left & impression & yes & yes & yes \\
\hline high & left & political & yes & yes & yes \\
\hline medium & middle & tourism & yes & yes & yes \\
\hline high & left & political & yes & yes & yes \\
\hline medium & middle & news & yes & yes & yes \\
\hline medium & middle & news & yes & yes & yes \\
\hline high & left & political & yes & yes & yes \\
\hline high & right & political & yes & no & yes \\
\hline high & right & political & yes & no & no \\
\hline & - & $\cdot$ & . & . & . \\
\hline low & right & impression & yes & no & no \\
\hline medium & right & news & yes & yes & no \\
\hline medium & left & impression & yes & yes & yes \\
\hline
\end{tabular}

Tabel 2 merupakan data training yang akan diolah dengan rapid miner untuk mendapatkan hasil klasifikasi data.

\section{B. Validation}

Validation dilakukan dengan analisis berbagai model dan memilih model dengan kinerja prediksi yang baik. Gambar berikut merupakan proses validasi menggunakan cross validation, setelah pembacaan file data, blok read excel dihubungkan dengan blok cross validation. Proses data mining berada didalam proses (cross validation) dapat ditampilkan dengan cara melakukan double klik pada mouse sehingga muncul proses training dan testing.

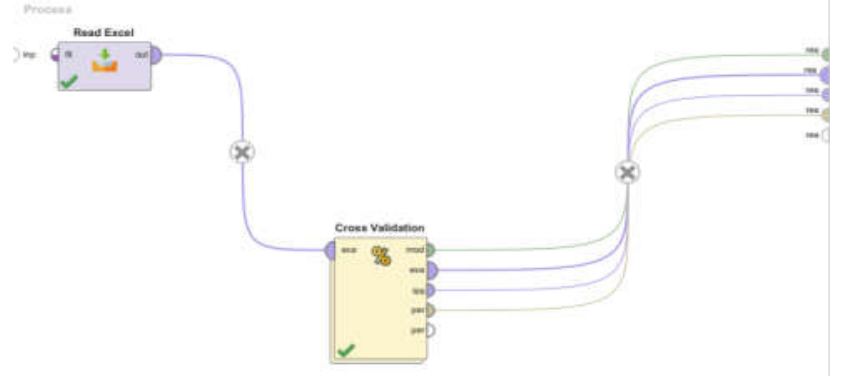

Gambar 2. Validation

Gambar 2 merupakan proses validasi menggunakan model olah data 10 fold dan cross validation.

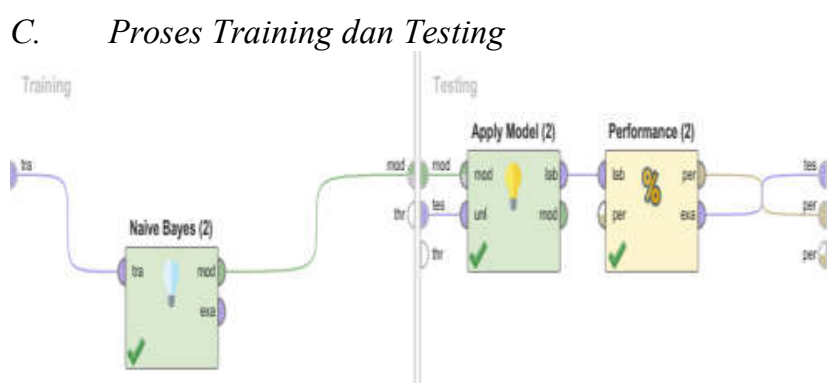

Gambar 3. Proses Training dan Testing

Gambar 3 merupakan proses training dan testing data menggunakan model 10 fold dalam rapid miner.

\section{Hasil Performance Vector}

Proses klasifikasi dengan rapid miner studio dengan metode naïve bayes yang digunakan untuk mengklasifikasikan data blogger pada penelitian ini menghasilkan accuracy, precision, dan recall.

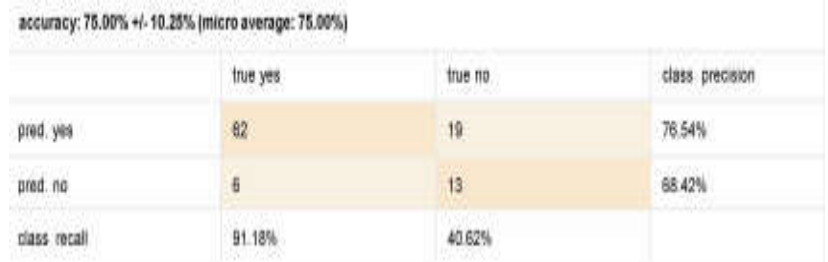

Gambar 4. Hasil Performance Vector

Perhitungan performance vector pada gambar 4 menunjukkan akurasi klasifikasi menggunakan metode Naive bayes diperoleh sebesar 75,00\% +/- 10,25\%. Sedangkan class precision dan class recall untuk prediksi yes menunjukkan tingkat precision sebesar $76,54 \%$ dan untuk prediksi no sebesar $68,42 \%$.

\section{E Hasil Klasifikasi Class dengan Metode Naïve Bayes}

1. Simple Distribution Models

Dengan menggunakan software rapid miner studio untuk menganalisis tabel data blogger dengan menggunakan metode naïve bayes dapat menghasilkan beberapa kelas utama pembagian sebagai berikut :

\section{SimpleDistribution}

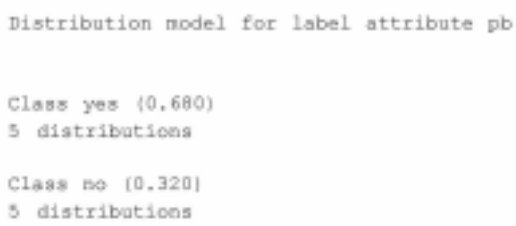

Gambar 5. Simple Distribution

Gambar 5 merupakan hasil klasifikasi dari data blogger dengan metode naïve bayes membagi 2 kelas klasifikasi PB yaitu class yes dan class no. Untuk nilai class yes yaitu 0.680 dan nilai class no yaitu 0.320 . 


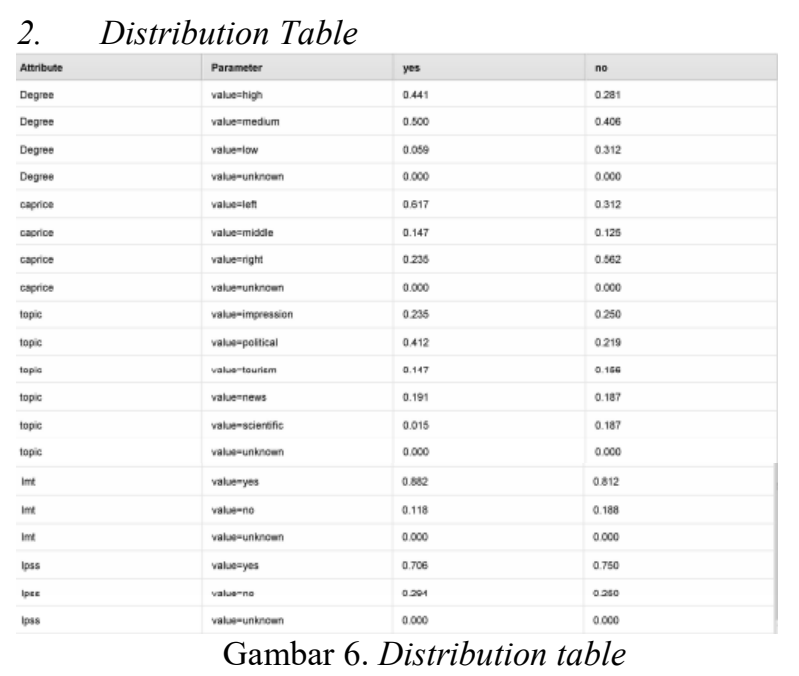

Gambar 6 merupakan distribution table hasil dari olah data rapid miner. Dari distribution table yang ada dapat diketahui hasil klasifikasi data blogger professional dan blogger musiman.

Selain menggunakan rapid miner, hasil klasifikasi data blogger yang ada pada distribution table juga dibuktikan dengan dihitung secara manual menggunakan microsoft excel. Berikut merupakan gambar perhitungan manual menggunakan microsoft excel:

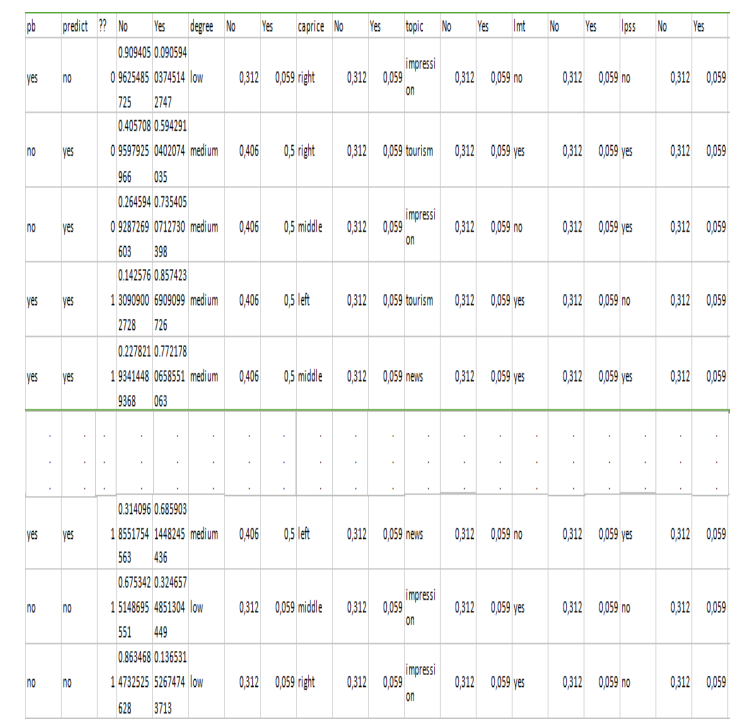

Gambar 6. Hasil perhitungan manual menggunakan microsoft excel

Gambar 6 merupakan hasil dari perhitungan manual yang dilakukan dengan microsoft excel. Dari hasil perhitungan manual tersebut dapat dilihat bahwa hasil yang ada pada distribution table di rapid miner sama dengan hasil perhitungan manual yang dilakukan menggunakan microsoft excel, dengan demikian dapat diambil kesimpulan bahwa akurasi klasifikasi data blogger ini baik.

\section{KESIMPULAN}

Berdasarkan hasil penelitian yang dilakukan, dapat dikatakan bahwa pengolahan data untuk mengklasifikasikan dataset blogger menggunakan algoritma naïve baDyes memiliki hasil yang baik dan dapat dijadikan sebagai acuan bagi orang-orang yang ingin mengetahui klasifikasi blogger musiman atau blogger professional. Selain menggunakan software rapid miner studio, peneliti juga mencoba untuk mengolah dataset blogger secara manual dengan menggunakan salah satu data testing sebagai prediktor untuk acuan pembuktian tingkat akurasi klasifikasi dari pengelompokkan data blogger. Dari hasil pengolahan data manual dan pengolahan data menggunakan bantuan software rapid miner studio, dapat disimpulkan bahwa hasil akurasi pengolahan data blogger menggunakan metode naïve bayes adalah baik.

$$
\text { Pengolahan dataset }
$$

blogger untuk mengklasifikasikan data blogger profesional dan blogger musiman sebaiknya ditambahkan dengan algoritma klasifikasi data mining yang lain agar dapat dilakukan perbandingan hasil penelitian dengan menggunakan beberapa algoritma sehingga dapat diketahui algoritma mana yang menghasilkan tingkat akurasi terbaik dalam proses klasifikasi data blogger.

\section{REFERENSI}

[1.] Ardiyansyah, Rahayuningsih, P. A., \& Maulana. R., (2018). Analisis Perbandingan Algoritma Klasifikasi Data Mining Untuk Dataset Blogger Dengan Rapid Miner, VI(1), 20-28.

[2.] Darmawan, A., Kustian, N., Rahayu, W., \& Tabebuya. (2018) Implementasi Data Mining Menggunakan Model Svm, 2(3), 299-307.

[3.] Hermawati, Fajar Astuti. (2013). Data Mining. Yogyakarta: Andi Offset

[4.] Kusrini, Luthfi, Emha Taufiq. (2013). Algoritma Data Mining. Yogyakarta: Andi Offset

[5.] Moriesta, E., \& Ibrahim, A. (2017). Analisis Penyaringan Email Spam Menggunakan Metode Naive Bayes, 3(1), 45-48.

[6.] Pratiwi Riszki Wijayatun, N. Y. S. (2016). Prediksi Rating Film Menggunakan Metode Naïve Bayes. Jurnal Teknik Elektro (ISSN 1411-0059), $\quad 8(2), \quad 60-63$. https://doi.org/10.7454/global.v19i1.136

[7.] Saleh, A., \& Nasari, F. (2018). Penggunaan Teknik Unsupervised Discretization pada Metode Naive Bayes dalam Menentukan Jurusan Siswa Madrasah Aliyah. Jurnal Teknologi Informasi Dan Ilmu Komputer, 5(3), 353. https://doi.org/10.25126/jtiik.201853705

[8.] Sari, F., \& Saro, D. (2018). Jurnal Penelitian Pos Dan Informatika Keluarga Berencana Di Kecamatan Dumai Timur Implementation Of Algorithm C4.5 To Determining Location Priority Counseling Family Planning Program In East Dumai Abstrak, 8(1), 63-76. Https://Doi.Org/10.17933/Jppi.2018.080105

[9.] Jeremy, A., Christanti, V., \& Mulyawan, B. (2018). Opinion Mining Untuk Ulasan Produk Dengan Klasifikasi Naive Bayes. Jurnal Ilmu Komputer Dan Sistem Informasi, 6(1), 9.

[10.] Murdiansyah, A. O., \& Siswanto, S. (2018). Algoritma Naive Baiyes Classsifier Pada Aplikasi Data Mining Berbasis WEB. SKANIKA, 1(1), 284-290. 